Trivium: Estudos Interdisciplinares, Ano XIII, Ed. 2. p. 3-20.

http://dx.doi.org/10.18379/2176-4891.2021v2p.3

\title{
O lugar atribuído aos pais no sofrimento do adolescente
}

\author{
Rita Hentz* \\ Daniel Kupermann ${ }^{* *}$
}

\begin{abstract}
Resumo
Por meio de uma pesquisa qualitativa, buscou-se investigar que lugar os adolescentes atribuem às figuras parentais no seu sofrimento psíquico. Participaram do estudo quatro jovens com idades entre 16 e 19 anos por meio de uma entrevista e o material coletado foi analisado através do método de Análise Interpretativa proposto por Frederick Erickson e interpretado a partir da teoria psicanalítica. As narrativas dos participantes resultaram no desenvolvimento das seguintes asserções: "A confusão de línguas entre os adolescentes e seus pais versus conflitos geracionais" e "A carência de relações significativas entre pares na adolescência", que propõem uma reflexão sobre as relações entre pais e filhos na adolescência.
\end{abstract}

Palavras-chave: ADOLESCÊNCIA; PSICANÁLISE; PAIS; CONFUSÃO DE LÍNGUAS; PAIS; CONFLITOS GERACIONAIS.

\section{The place attributed to parents in the adolescent's suffering}

\begin{abstract}
Through a qualitative research, we sought to investigate where adolescents place parental figures in their psychological distress. Four young people aged between 16 and 19 participated in the study through an open interview and the material collected was analyzed using the Interpretive Analysis Method proposed by Frederick Erickson and interpreted from the psychoanalytic framework. The participants' narratives resulted in the development of the following assertions: "The confusion of languages between adolescents and their parents versus generational conflicts" and "The lack of significant relationships between peers in adolescence", providing a reflection on the relationships between parents and their adolescent children. Keywords: ADOLESCENCE; PSYCHOANALYSIS; PARENTS; LANGUAGE CONFUSION; GENERATIONAL CONFLICTS.
\end{abstract}

\footnotetext{
${ }^{*}$ Psicanalista, Psicóloga pela PUCRS, Mestre em Psicologia Clínica pela Universidade de São Paulo, aluna do curso de Formação em Psicanálise do Instituto Sedes Sapientiae e membro do Grupo Brasileiro de Pesquisas Sándor Ferenczi.

ORCID ID: https://orcid.org/000-0003-1920-6028

E-mail: hentzrita@hotmail.com

** Psicanalista, Professor Livre Docente do Departamento de Psicologia Clínica da Universidade de São Paulo e bolsista do CNPq- Brasil.

ORCID ID: https://orcid.org/000-0003-1833-9136

E-mail: danielkupermann@gmail.com
} 
El lugar atribuido a los padres en el sufrimiento de los adolescentes

\section{Resumen}

Mediante una encuesta cualitativa, se buscó investigar cuál es el lugar que los adolescentes atribuyen a las figuras parentales en su sufrimiento psíquico. En el estudio participaron cuatro jóvenes con edades entre 16 y 19 años por medio de una entrevista y el material que se recolectó fue analizado mediante el método de Análisis Interpretativo propuesto por Frederick Erickson e interpretado a partir de la teoría psicoanalítica. Las narrativas de los participantes resultaron en el desarrollo de las siguientes aserciones: "La confusión de lenguas entre los adolescentes y sus padres versus conflictos generacionales" y "La carencia de relaciones significativas entre pares en la adolescencia", las cuales proponen una reflexión sobre las relaciones entre padres e hijos en la adolescencia.

Palabras clave: ADOLESCENCIA; PSICOANÁLISIS; PADRES; CONFUSIÓN DE LENGUAS; CONFLICTOS GENERACIONALES.

\section{Introdução}

Do ponto de vista do desenvolvimento humano, a adolescência é definida como um período biológico em que o jovem adquire um corpo adulto e se depara com a tarefa de reconhecer-se como sujeito a partir desta nova configuração física. Além disso, nesta fase, os pensamentos, as opiniões e as capacidades cognitivas transformam-se, tornandose possível pensar abstrata e hipoteticamente, por exemplo (Papalia, 2006). Segundo a Organização Mundial da Saúde (OMS), este estágio é caracterizado socialmente como um tempo que designa uma etapa de transição entre a infância e a idade adulta, e acontece entre os 10 e os 19 anos. Já no Brasil, o Estatuto da Criança e do Adolescente (ECA) define a adolescência como uma faixa etária que ocorre dos 12 aos 18 anos de idade. Historicamente, a adolescência é um fenômeno relativamente recente, já que, até o século XVIII, as etapas da vida eram divididas em infância, juventude, adultez e velhice. Faz mais ou menos um século que a adolescência passou a ser considerada um grupo social reconhecido, visto que, ao longo dos anos, surgiu uma necessidade de separar os mais jovens dos adultos.

Já para a Psicanálise, a adolescência vai muito além das transformações corporais e sociais e a complexidade deste período demonstra a necessidade de um olhar amplo, que envolva os diversos desdobramentos relativos a esse processo. É importante, portanto, refletir sobre as diversas demandas impostas ao jovem para compreender o vasto campo de possibilidades com que o sujeito se depara nesta etapa da vida (Macedo, Azevedo \& Castan, 2010).

Ainda que Sigmund Freud não tenha utilizado o termo "adolescência" no decorrer de sua obra, no marcante ensaio "Três Ensaios sobre a Sexualidade" (1905/2006), ele explorou a fase da puberdade, considerando-a uma transição entre a infância e a vida adulta, que acarreta mudanças corporais e torna possível a genitalidade como um novo destino para a pulsão sexual. $\mathrm{O}$ autor afirmou ainda que, nesta fase, iniciam-se as escolhas de objetos exogâmicos - fora do núcleo familiar -, baseadas nas vivências sexuais infantis. Além disso, Freud (1905/2006) constatou que durante a latência - período entre o Complexo de Édipo e a puberdade - a criança adia aquilo que retornará logo mais, ou seja, na adolescência: a busca pelo prazer genital e a revivência do Complexo de Édipo. O incremento da pulsão sexual, ocorrido na puberdade, demanda a reorganização das pulsões parciais - culminando na escolha objetal definitiva. Sublinha-se que o uso que 
Freud fazia do termo puberdade não se restringia especificamente às transformações fisiológicas e, por mais que não discorresse sobre a adolescência propriamente dita, termo incomum na época, ele se referia à puberdade como o segundo momento da sexualidade humana. Sendo assim, ao destacar as transformações dos fatores biológicos e psíquicos próprios da puberdade, Freud (1905/2006) também inaugurou um amplo campo de reflexão sobre este assunto pouco estudado até então.

Atualmente, sabe-se que, na adolescência, a incontrolável maturação física impulsiona o sujeito a abrir mão da condição infantil e a construir uma nova identidade. Para isso, o adolescente revisa seu mundo interno e suas vivências infantis, na tentativa de dar conta das mudanças físicas repentinas e do intenso trabalho psíquico que essa fase da vida demanda. Assim, considera-se que esse período da vida vem acompanhado por uma dose de sofrimento psíquico, oriundo de todas essas transformações e esse sofrimento, portanto, é considerado inerente, uma vez que está relacionado ao que é inseparável e constitutivo nesse processo de adolescer.

Além da árdua tarefa de elaborar o luto do corpo infantil, o sujeito precisa elaborar o luto dos pais da infância e preparar-se, assim, para investir no futuro, em novos objetos e construir uma nova identidade (Savietto

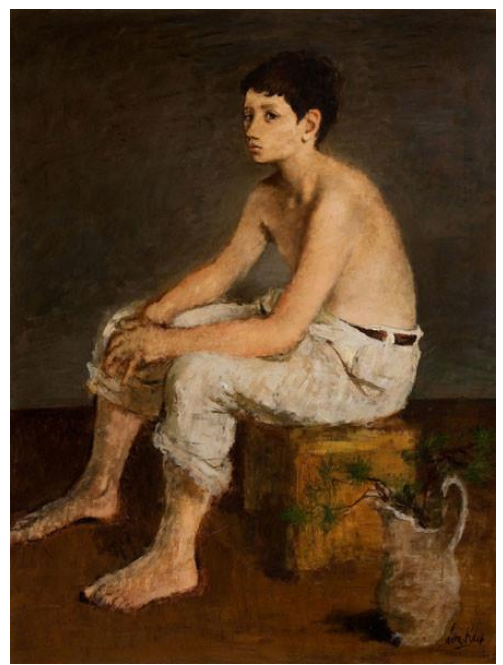

Leon Karp - Adolescence (1944) \& Cardoso, 2006). Savietto (2010) define a adolescência como uma "experiência transbordante e apassivadora" (p.17), na qual o sujeito revive a experiência constitutiva de desamparo, precisando se reconhecer em um corpo de um adulto e necessitando de referências - que não sejam as figuras parentais - para identificar-se.

Na mesma direção, Nasio (2010) define este período como um longo e doloroso processo de luto, no qual o jovem precisa de um tempo para aceitar e conviver com a ausência definitiva daquilo que ama, mas que foi perdido e esse processo faz com que, recorrentemente, os adolescentes sintam-se frágeis, confusos, inseguros, impotentes e desamparados (Savietto \& Cardoso, 2006). Neste sentido, as variadas demandas sociais, familiares e culturais somadas às incontroláveis transformações psíquicas e afetivas, próprias da adolescência, acarretam um inexorável sofrimento a essa fase da vida.

Para esta investigação, partiu-se da hipótese de que algumas situações familiares vivenciadas pelo jovem, somadas às problemáticas próprias da adolescência, poderiam caracterizar um excesso de sofrimento. Esse excesso seria então, uma intensificação do sofrimento adolescente, o qual ultrapassa o sofrimento inerente e esperado nesta fase da vida e poderiam se manifestar, segundo Mannoni (1996), de diferentes formas, como pelo uso exagerado da autoridade ou pela ausência total desta, pelas recomendações incessantes ou pelo silêncio.

Donald Winnicott, um dos psicanalistas mais importantes no que se refere à adolescência, salienta que essa fase pode vir acompanhada por uma oscilação entre rebeldia e dependência:

aqueles que cuidam de adolescentes não raro veem-se perplexos com o fato de que esses meninos e meninas, por vezes tão rebeldes, podem também ser, ao mesmo tempo, dependentes a ponto de parecerem crianças e mesmo bebês, manifestando padrões de dependência que talvez remontem aos primeiros meses de vida (Winnicott, 1961/2013, p. 123). 
Segundo Winnicott $(1956 / 2000 ; 1988 / 1990)$, o amadurecimento segue um percurso que se inicia com a dependência absoluta de um outro até a independência relativa, alcançada na maturidade. Sobre esse amadurecimento, resumidamente, entendese que o bebê nasce imaturo e desamparado, dependendo completamente de um ambiente que o acolha e o ajude a tornar-se um sujeito integrado que se relaciona com outros. Esse ambiente é, de um modo geral, representado pela mãe, que deve desenvolver uma identificação com o seu bebê, atendendo-o em suas necessidades. Dessa maneira, o conceito de "mãe suficientemente boa" caracteriza aquela capaz de reconhecer as necessidades do seu bebê, oferecendo a ele um ambiente seguro, acolhedor e possibilitando, dessa forma, que o bebê se desenvolva.

A importância de um ambiente suficientemente bom retorna na adolescência, quando o jovem, imaturo e vulnerável, depende de um ambiente firme, seguro e acolhedor, que o auxilie a constituir sua nova identidade (Oliveira \& Fulgêncio, 2010). Vale ressaltar que o adolescente, na maioria das situações, não consegue verbalizar o que sente, e nesses momentos transfere, consciente ou inconscientemente, ao adulto a função de perceber e compreender seus sentimentos, esperando que esta figura o auxilie na tradução de seu próprio mal-estar (Winnicott 1963/2016).

Assim, no enfrentamento da adolescência, faz-se importante não apenas as capacidades internas do sujeito para lidar com as novas demandas, mas também a necessidade de que os pais sustentem ativamente este processo de adolescer. Kupermann (2007) sublinha as relevantes ideias winnicottianas em relação ao paradoxo que a adolescência representa: o jovem deseja e precisa experenciar a sua rebelião, entretanto, necessita de um ambiente seguro, que o acolha, o proteja e o contenha nessa turbulência e as patologias mais graves que acometem o adolescente podem estar denunciando um não vivido, que possivelmente decorre da falta de sustentação dessa "revolta" por parte dos pais.

Os pais são, então, fundamentais no desenrolar da conflitiva adolescente, devendo participar de maneira ativa dos conflitos dos jovens por meio da sensibilidade de assimilar as manifestações dos filhos para além da palavra. Quando o adulto não está disponível para ocupar esse lugar, no entanto, o jovem se depara com a impossibilidade de colocar em palavras o que lhe acomete e essa possível precariedade de investimento poderá acarretar em uma fragilidade psíquica e ser causadora intenso sofirmento para o adolescente (Birman, 2006; Nasio, 2010). Nesta direção, Winnicott (1961/2013, p.117) indica que "muitas das dificuldades pelas quais passam os adolescentes, e que muitas vezes requerem a intervenção de um profissional, derivam de más condições ambientais; este fato apenas serve para enfatizar a vital importância do ambiente e da família".

Embora a adolescência traga numerosas dificuldades tanto para o próprio jovem como para quem os cuida, Winnicott (1964/2016) chama a atenção para o fato de que não é possível impedir, encurtar ou retardar esse processo, uma vez que a adolescência é natural e necessária para a conquista da maturidade. A partir dessa reflexão, o autor conclui que "de fato, existe somente uma cura real para a adolescência: o amadurecimento. Isso, somado a passagem do tempo, resulta, no final, no surgimento da pessoa adulta" (p. 163). Aos pais, cabe a função de sobreviver a esse período e não retaliar os filhos.

Apesar da importante teorização já existente sobre essa temática, a adolescência permanece como um desafio para a psicanálise e a dinamicidade dos conflitos frente às demandas familiares, sociais e culturais convoca a atualização constante do estudo sobre esta etapa. Partindo do raciocínio teórico, brevemente descrito até aqui, a investigação, em nível de Mestrado e conduzida entre 2017 e 2019 no Programa de Pós-Graduação em Psicologia Clínica do Instituto de Psicologia da Universidade de São Paulo, teve o 
objetivo de compreender, a partir da narrativa do adolescente, qual é o lugar atribuído aos pais ${ }^{1}$ no seu sofrimento psíquico.

\section{Método}

Para a realização desta pesquisa, optou-se pelo método de cunho qualitativo e de caráter exploratório. Conforme Nunes (2004), a abordagem qualitativa na condução de uma pesquisa possibilita fazer descobertas, compreender novos significados sobre as questões em estudo e avaliar alternativas. Por outro lado, esse tipo de abordagem mantém a possibilidade de confirmação do que já foi constatado, verificando-se frequentemente esses conhecimentos, que nunca devem ser entendidos como prontos e acabados (Turato, 2011).

Desta forma, após o trâmite ético necessário e a aprovação do Comitê de Ética em Pesquisa com Seres Humanos do Instituto de Psicologia da Universidade de São Paulo, iniciaram-se os procedimentos previstos no estudo. A coleta de dados foi realizada por meio de uma entrevista de tempo indeterminado e com questões abertas com eixos temáticos pré-estabelecidos, que foram os seguintes: história de vida, relação com as figuras parentais, experiências significativas da adolescência e estratégias para lidar com o sofrimento psíquico. Entende-se que as questões norteadoras das entrevistas serviram como um norte na busca de dados. Conforme Turato (2011), a flexibilidade oferecida por essa modalidade de entrevista permite que o pesquisador proponha uma entrevista seguindo os eixos temáticos, mas mantendo aberto o espaço para que sejam apresentados novos questionamentos a partir da fala do entrevistado.

Os jovens foram selecionados através da técnica denominada Bola de Neve (Turato, 2011) que consiste na identificação de um primeiro participante, que indica o segundo e, assim, sucessivamente. Participaram desta pesquisa quatro adolescentes com idades entre 16 e 19 anos, residentes da cidade de São Paulo, e passaram a fazer parte deste estudo somente após a assinatura do Termo de Consentimento Livre e Esclarecido. Sobre os participantes, é interessante ressaltar a diversidade em relação à renda. Apesar de não ter sido aplicada uma ficha de dados pessoais e sociodemográficos que comprovasse as diferenças sociais entre os jovens, foi possível perceber, a partir das narrativas, que eles pertenciam a diferentes classes sociais, ressaltando que o sofrimento adolescente não se restringe a determinadas configurações familiares de baixa renda, por exemplo.

Para auxiliar o leitor na compreensão das vinhetas que serão apresentadas posteriormente, elaborou-se um breve resumo sobre os quatro participantes. Uma das participantes $^{2}$, Sara, 16 anos, mora com a mãe e com o irmão mais novo e estudou durante toda a sua vida nos melhores colégios particulares de São Paulo. Apenas no final da entrevista, mencionou que os seus pais se haviam separado, sendo este o único momento em que chorou. Relatou que tem muita dificuldade de estabelecer amizades e contou sobre os conflitos incessantes que vivencia com a mãe. Outro participante, Breno, 19 anos, filho único, nasceu em São Paulo e reside apenas com a mãe desde a separação dos pais - que aconteceu quando o jovem tinha 13 anos. Breno relata ter uma relação difícil com a mãe, sendo que, em uma das brigas entre os dois, ele precisou se mudar para a casa do pai, em outro estado, por seis meses. Outro participante, Arthur, 19 anos, vive com a mãe, o padrasto e o meio-irmão em São Paulo e sempre enfrentou dificuldades financeiras. Os pais se separaram quando ele tinha 12 anos, sendo que o pai é descrito como ausente pelo jovem. Sobre o casamento dos pais, conta do sofrimento de presenciar as inúmeras brigas entre eles, relatando que o pai, alcoólatra, agredia a mãe diariamente. Logo após a 
separação, a mãe se casou com o padrasto, que, segundo o jovem, também é alcoólatra, agressivo com a esposa e viciado em jogos. $\mathrm{O}$ adolescente relata que o padrasto sempre o menosprezou e que a mãe não o defendia. Arthur mencionou que, além de não ter amigos no colégio, sofria bullying. Letícia, 18 anos, morou durante quase toda a sua vida com a avó materna, que é considerada pela jovem como mãe. Quando nasceu, seu pai foi embora e nunca mais voltou e, além disso, a mãe começou a rejeitá-la. Demonstra uma fala desorganizada, confusa e com partes incongruentes. Parou de estudar aos quinze anos, já que precisou trabalhar e ajudar em casa.

Para a análise dos dados, utilizou-se o método denominado "Análise interpretativa", de Frederick Erickson (1997), que consiste na elaboração de asserções a partir da escuta e leitura das entrevistas realizadas. O termo "asserção", utilizado por Erickson para explicar o método da Análise Interpretativa, pode ser compreendido como uma afirmação categórica que enuncia o resultado ou um dos resultados da pesquisa. Nesta metodologia, a principal tarefa do pesquisador é descobrir os diferentes estratos de universalidade e de particularidades presentes nos casos estudados, ou seja, discriminar quais aspectos podem generalizar-se para outras situações similares e quais são exclusivos do caso em questão. A proposta central é que os dados coletados (entrevistas) conduzam a posterior teorização. A apresentação das asserções é ilustrada com vinhetas e fundamentada com comentários interpretativos, que, no estudo em questão, são sustentados na teoria psicanalítica.

Esse método, que foi proposto em 1997 por Frederick Erickson, professor norteamericano de Antropologia e Educação, é encontrado, sobretudo, em artigos e pesquisas da área educacional. Há alguns anos, a metodologia também começou a ser aplicada em algumas pesquisas psicanalíticas, entendendo-se que pode dialogar com a Psicanálise, na medida em que valoriza a singularidade de cada entrevistado e, ao mesmo tempo, evidencia os contextos que podem estar sendo compartilhados de forma coletiva pelos participantes de um estudo. É válido destacar que o material que será apresentado neste capítulo representa uma breve parcela dos resultados, e não a íntegra das asserções desenvolvidas na pesquisa. Esta pesquisa, então, está relacionada ao que Freud (1917/1980) chamou de psicanálise aplicada, que diz respeito ao fato de que a teoria psicanalítica não se reduz à prática terapêutica e tampouco à psicologia individual, mas pode ser extensiva à cultura, à literatura, aos mitos, à arte, à religião, dentre outras áreas do conhecimento, tendo em vista que o inconsciente está presente em toda manifestação humana e sua investigação não precisa e não deve se restringir a prática clínica.

\section{Resultados e Discussão}

Após a transcrição das entrevistas e a análise do material obtido, foram formuladas duas asserções. A primeira asserção foi denominada: "A confusão de línguas entre adolescentes e seus pais versus conflitos geracionais", a qual foi dividida em três subtítulos: o descuido à assimetria, conflitos geracionais e a potencialidade traumática da confusão de línguas. Propõe-se uma releitura do conceito ferencziano de "confusão de línguas" no contexto da adolescência, releitura esta que se coloca como uma proposta teórica que surgiu a partir da escuta das entrevistas e da posterior rememoração dessa noção ferencziana. Apresenta-se primeiramente uma teorização sobre o conceito ferencziano, seguida de uma reflexão sobre o atravessamento da confusão de línguas nas relações entre adultos e adolescentes, contrapondo esse contexto à ideia de conflito geracional, baseando-se, principalmente, nas teorizações dos psicanalistas Sándor Ferenczi e Donald Winnicott. A segunda asserção recebeu a seguinte denominação: "A carência de relações significativas entre pares na adolescência", e abordou conteúdos 
inesperados manifestados nas entrevistas que, apesar de não remeterem diretamente ao objetivo inicial da pesquisa, evidenciaram um contexto merecedor de atenção e reflexão.

Desse modo, a seguir, serão discutidas as asserções, que foram ilustradas por meio das entrevistas realizadas e interpretadas a partir da teoria psicanalítica. Salienta-se que serão apresentadas apenas algumas vinhetas consideradas mais ilustrativas e não a entrevista na íntegra e que, no final de cada relato constará o nome fictício e a idade do participante com o propósito de auxiliar a leitura. Por fim, relembra-se que todo o material apresentado representa a realidade psíquica do jovem sobre as relações e os acontecimentos por ele vivenciados, e não pretende culpabilizar o adulto, mas explorar quando e de que forma a relação com as figuras parentais pode se tornar fonte de sofrimento para o adolescente.

\section{A confusão de línguas entre adolescentes e seus pais versus conflitos geracionais $\mathrm{O}$ descuido à assimetria}

Em 1933, na contramão do pensamento freudiano vigente na época, o psicanalista Sándor Ferenczi apresenta o texto "Confusão de língua entre os adultos e a criança (A linguagem da ternura e da paixão)" ressaltando a importância do fator traumático real e justificando que o mesmo estava sendo injustamente negligenciado - referindo-se à teoria freudiana que relacionava o trauma às expressões de fantasias edipianas. $\mathrm{O}$ autor justifica, a partir de sua prática clínica, a hipótese de que "nunca é demais insistir sobre a importância do traumatismo, e, especialmente, do traumatismo sexual como fator patogênico" (Ferenczi, 1933/2011, p.116). A partir dessa enunciação, é que foi desenvolvido o texto ferencziano que aponta para a existência de uma confusão entre as linguagens da criança e do adulto que se manifestam de diferentes formas e nos mais variados contextos.

A confusão de línguas diz respeito ao fato de que a criança e o adulto comunicamse fazendo uso de línguas diferentes - enquanto a criança se comunica a partir da linguagem da ternura, o adulto já está marcado pela linguagem da paixão, sendo que a primeira se refere à linguagem lúdica, evocativa, constitutiva de si e do mundo, e a segunda como uma linguagem dominadora, que supostamente portaria uma verdade inquestionável (Ferenczi, 1933/2011; Kupermann, 2019). Ainda que o texto de 1933 trate, principalmente, da relação entre adultos e crianças, em determinado momento Ferenczi utiliza como exemplos de confusão de línguas a prática de atos sexuais impostos ou o caso de uma mulher adulta, que já atingiu a maturidade, mas que se relaciona sexualmente com um adolescente - usando como ilustração a situação de uma governanta de família nobre que mantinha uma vida conjugal com adolescentes deste núcleo familiar.

Convém considerar, portanto, que a criança descrita por Ferenczi (1933/2011) não está relacionada apenas com determinada idade cronológica, mas sim com um sujeito que se encontra em estado de vulnerabilidade. A linguagem da ternura, então, se refere a um convite à relação de cuidado - o que, obviamente, não se restringe à infância (Kupermann, 2019). Sendo assim, baseando-se nas narrativas dos entrevistados, propomos que a linguagem da ternura não se refere somente à criança, mas também ao adolescente apesar de nestes casos, se expressar por outras nuances.

Os comportamentos adolescentes também estão associados à linguagem da ternura, já que reportam ao desejo de ser cuidado, mesmo que de forma contraditória, e as experimentações próprias desta fase. Logo, a confusão de línguas que se faz presente nesta asserção está relacionada a um descuido com a assimetria entre o adulto e o adolescente, manifestada nas entrevistas de diferentes formas, como por exemplo: o adulto que não sustenta o seu lugar e trata o adolescente como um par ou se comporta 
como alguém mais frágil e imaturo do que o próprio jovem, esperando do adolescente uma postura que ainda não lhe compete, passagem ao ato muito rápida por parte do adulto por meio de uma punição imediata ao jovem, pela humilhação ou negligência afetiva.

É pertinente lembrar também da ênfase dada por Ferenczi (1933/2011) ao fenômeno da progressão traumática - que diz respeito a um amadurecimento precoce na vida do sujeito - como sendo uma das possíveis reações frente à confusão de línguas. Segundo o autor, quando ocorre um grave abandono ou uma grande aflição na vida da criança, há um despertar de capacidades que só deveriam se manifestar na idade adulta (Kupermann, 2006). Para refletir sobre essa questão, Ferenczi lança mão de uma interessante metáfora: "Pensa-se nos frutos que ficam maduros e saborosos depressa demais, quando o bico de um pássaro os fere, e na maturidade apressada de um fruto bichado" (Ferenczi, 1933/2011, p. 119).

A partir das vinhetas dos entrevistados que serão mostradas a seguir, percebeu-se, de modo geral, há uma confusão de línguas, manifestada por uma troca de papéis, isto é, o adolescente precisando cuidar do adulto ou o adulto comportando-se como um adolescente, esperando do filho uma responsabilidade que não condiz com a sua posição. A narrativa de Breno, exposta a seguir, relata um acontecimento em que a diferença entre o adulto e o adolescente parece se esvair de forma a provocar intenso sofrimento:

"Eu tinha 13 anos, meu pai foi sair a trabalho, mas eles [pai e mãe] ainda não tinham se separado. Depois de um ano ele ficou com a amante dele, ele achou uma mulher lá em Curitiba, que é a atual esposa dele. Ele chegou a me apresentar ela sem a minha mãe saber, e eu fiquei pensando 'será que eu conto para minha mãe, será que eu não conto?'. Eu era muito novo pra entender essa situação e eu não entendia. E daí eu não sabia o que fazer" (Breno, 19 anos).

A vinheta atesta o descaso desse pai ao contar para o filho, que na época tinha apenas 13 anos, que mantinha um caso extraconjugal. Nessa situação, a confusão de línguas pode ser interpretada de duas formas: o pai agindo como um adolescente e equiparando-se ao filho, ou o pai tratando o filho como um amigo da mesma idade, deixando de lado a assimetria que deveria existir entre os dois.

Convém sublinhar que, por mais que Ferenczi priorize o exemplo do abuso sexual para explicar a origem da experiência traumática, o autor aborda também variadas modalidades de confusão de línguas, como a punição passional. Para explicar essa ideia, o psicanalista utiliza como ilustração o caso de uma criança, que comete um delito sem intenção, uma vez que ainda não tem dimensão da gravidade de suas ações, e o adulto a pune com um castigo exagerado (Ferenczi, 1933/2011). Ainda no discurso de Breno, pode-se pensar em um tipo de punição passional da mãe em relação ao filho:

"Uma vez que minha mãe veio querer me acordar 5h da manhã nas férias pra levar o lixo na rua, e eu disse que não ia. Daí ela pegou um cabo de vassoura e bateu muito em mim. Às vezes eu conseguia segurar ela e empurrar, e conta como uma agressão, mas eu considero uma defesa. Essas brigas físicas sempre acontecem por coisas pequenas, por exemplo por eu não lavar a louça, não arrumar o quarto. Eu ficava irritado, daí partia pra xingamento verbal, até que os dois se irritavam, daí ela pegava algo e vinha pra cima de mim me bater, com tudo. E eu tentava imobilizar ela. E depois eu normalmente me trancava no meu quarto pra não bater nela" (Breno, 19 anos).

Além do exemplo do abuso sexual e da punição passional, Ferenczi (1933/2011) indicou ainda uma terceira forma de ilustrar a confusão de línguas: o "terrorismo do 
sofrimento", que se refere às "crianças que são obrigadas a resolver toda espécie de conflitos familiares e carregam sobre seus frágeis ombros o fardo de todos os outros membros da família" (p. 120) - o que caracteriza uma inversão nas práticas do cuidado, já que a criança se responsabiliza pelo adulto que deveria acolhê-la e cuidá-la. A seguir, apresenta-se um trecho da entrevista da jovem Letícia, no qual a troca de papéis se manifesta em diferentes momentos da sua adolescência:

"Enquanto criança, morava com a minha avó. Depois fui morar com a minha mãe, eu tinha 13 anos. Quando eu morei com minha mãe, meu padrasto e meus irmãos, eu que fazia as coisas de casa. Fazia comida, lavava roupa... E meu padrasto, quando minha mãe chegava, ele brigava porque não queria que minha mãe trabalhasse. E todo final de semana, de sexta a domingo, pode contar que era briga... então, ele tem até hoje um corte no braço, que eu fiz com um pedaço de vidro, porque eu fiquei muito brava de ver aquilo ali. Como eu defendia a minha mãe, eu apanhava. Eu levava soco no nariz, soco na cabeça, ele me derrubava no chão. Ai, foi quando eu falei pra minha mãe, ou ela escolhia eu, ou ela escolhia ele. Mas quando eu pedi pra ela escolher entre eu e meus irmãos ou ele e ela escolheu ele [padrasto], eu fui morar com a minha avó lá em Osasco. E quando eu fui morar lá, ela começou a ficar doente e ninguém sabia o que era. E eu fiquei 1 ano e 8 meses sem estudar porque eu não largava dela pra nada" (Letícia, 18 anos).

O discurso da adolescente denunciou uma total inversão nas práticas de cuidados em diferentes sentidos. Letícia foi abandonada pelo pai e rejeitada pela mãe quando nasceu e, por esta razão, morou com a avó materna durante sua infância. No início da adolescência da menina, a mãe exigiu que a filha morasse com ela, com o novo companheiro e com os meios irmãos. Mas nesse novo contexto, a jovem, mais velha entre os filhos passou a ser responsável pelas tarefas domésticas, pelos cuidados com os irmãos, além de ser violentada pelo padrasto por tentar proteger a mãe das agressões do marido. Quando sentiu a situação intolerável e pediu para que a mãe escolhesse entre ela ou o padrasto, viu-se mais uma vez preterida, já que a mãe preferiu o marido.

Diante do novo abandono, Letícia voltou a morar com a avó, na esperança de ser cuidada; porém, precisou deixar de ir à escola para tomar conta da avó, que estava doente. Todos esses fatores demonstram a falta de uma figura de referência que acolhesse e cuidasse da jovem. Amparando-se, porém, na teorização ferencziana, pode-se imaginar que a confusão de línguas, neste caso, ocorreu por meio do terrorismo do sofrimento, que obrigou Letícia a carregar sobre seus ombros o fardo de todos os outros membros da família (Ferenczi, 1933/2011). Nesta mesma direção, o seguinte relato de Arthur, também indica uma responsabilização inadequada por outros membros da família, além de uma humilhação do jovem por parte das figuras parentais:

"Tudo que acontecia era culpa minha. O filho mais novo do meu padrasto tinha um problema na cabeça e daí teve um dia que eles [os dois irmãos, filhos do padrasto] brigaram e eu tava [sic] jogando vídeo game. E eu não vou fazer nada, porque se eu entrar na briga eu vou apanhar também. E aí eu deixei eles brigando lá. E aí um bateu a cabeça na pia, daí meu padrasto chegou em casa [sic] e falou que era culpa minha, que os dois tavam [sic] brigando, que, não sei o quê, e que eu machuquei o mais novo e eu fiquei 'meu, mas eu não fiz nada!' E assim, parece que ele me odeia e sempre quis me diminuir. Teve uma vez que era Páscoa, a gente foi no [sic] mercado comprar ovos de páscoa e a gente chegou no [sic] mercado e ele comprou dois ovos grandes pra cada filho dele e aí ele chegou no [sic] caixa do supermercado e comprou um 
bombom. E aí os filhos dele vieram todos felizes no carro com os dois ovos, e aí ele falou “ó, comprei pra você" e me deu um bombom" (Arthur, 19 anos).

A fala revela que, além de o padrasto esperar do enteado uma responsabilização pelos seus próprios filhos - que tem a mesma idade do jovem -, parece fazer questão de diminuir a importância do enteado diante da família, tratando Arthur com evidente hostilidade. Perante esses comportamentos, questiona-se ainda o lugar da mãe nessas situações, a qual poderia defender o filho, mas que parece não o fazer. Nota-se ainda na história de vida de Arthur, que a confusão de línguas entre o jovem e as figuras parentais provoca intenso sofrimento para o adolescente e parece obrigá-lo a assumir uma postura de adulto precocemente:

"Meu padrasto é aquele tipo de pessoa que tem 45 anos, por aí, mas ele parece um menino de 18, só quer zoar. E ele só fecha trabalho bom, o mais barato que ele fechou agora foi de 30 mil. E assim, cadê o dinheiro? Não vejo dinheiro. A gente mora de aluguel, falta bastante coisa, às vezes, e não vê dinheiro. Porque assim, antigamente ele era usuário, ele usava mais. Hoje ele só fuma maconha, fuma muito por sinal. Mas ele também, por noite, ele gasta no bar que ele vai [sic] com os amigos, toda noite, ele gasta 300, 400 reais" (Arthur, 19 anos).

Observa-se que o jovem enxerga o padrasto como um "moleque de 18 anos que só quer zoar", já que o mesmo age como um adolescente mais novo que o próprio Arthur, esquecendo-se das responsabilidades que deveria ter e comportando-se de forma inconsequente. $\mathrm{O}$ mesmo participante, nos trechos a seguir, continua narrando as suas dolorosas experiências:

“A relação com a minha mãe é assim meio complicada porque ela quer me encher de coisa, e porque eu já não tenho muito tempo, não tenho tempo nem pra mim e ela quer me encher de coisas, ela quer que eu faça muita coisa sem eu poder (...). E assim, eu não sou mais uma criança, com todo esse meu passado, eu fui obrigado a crescer muito rápido, mais rápido do que eu deveria. Às vezes, eu fico pensando assim que eu tenho uma cabeça que não era pra eu ter, era pra eu ser mais infantil sabe? E minha mãe não entende, ela acha que tenho que ter responsabilidade de um adulto, mas não posso ter nenhuma liberdade assim. Eu perdi toda a minha infância, eu perdi minha infância e minha adolescência, então eu cresci muito rápido né” (Arthur, 19 anos).

Compreende-se que essas situações obrigaram Arthur a sair, violentamente, da posição de adolescente e assumir uma posição de adulto - arcando com responsabilidades que as figuras parentais não se encarregaram por ele - caracterizando o que Ferenczi (1933) chamou de progressão traumática.

\section{Conflitos geracionais}

Não há como, e nem seria positivo, evitar a presença de conflitos entre os adolescentes e as figuras parentais, já que existe uma diferença de posições e de momentos de vida e, em consequência disso, os valores, as opiniões, os desejos e as ideias entram, constantemente, em confronto. Os conflitos dessa ordem foram chamados de geracionais e considerados, nesta pesquisa, como inexoráveis ao processo de adolescer e não são entendidos como traumáticos. Certo afastamento entre pais e filhos é esperado, já que se trata de um período marcado pela diferenciação identitária das figuras de 
referência e pela consequente necessidade do jovem de criar sua própria identidade. No relato de Sara, observa-se um exemplo deste tipo de divergência entre as ideais da mãe e da filha:

"Ah, eu acho que tempos mudaram, então tem coisas que pra mim assim, pro pessoal da minha idade, parece muito mais normal e que a minha mãe sente que é muito pra frente. Por exemplo sobre a comunidade LGBT, sobre o uso de drogas na adolescência. $\mathrm{Eu}$ sou a favor dos relacionamentos abertos, ela não. Eu sou totalmente contra o Bolsonaro e ela ainda concorda com algumas ideias dele..." (Sara, 16 anos).

Nesta narrativa, verifica-se uma oposição de opiniões que não ocorre de uma maneira traumática - já que a divergência é respeitada por ambas as partes. Supõe-se, então, que esse tipo de discordância se enquadra no que propomos chamar de conflito geracional. Conflito de gerações pode ser definido como uma diferença estruturante existente entre a posição do adolescente e a do adulto, que não traz sofrimento para o jovem, pelo contrário, na maioria das vezes, oferece contenção. Seria uma modalidade de embate entre forças conservadoras, vindas da parte do adulto, e forças disruptivas, próprias do adolescente (Winnicott, 1971/1975). Esses confrontos auxiliam os jovens a enfrentarem a adolescência e são considerados por Winnicott como positivos e necessários, como salientado a seguir: "A confrontação é própria da contenção que não é retaliatória, nem vingativa, mas possui sua própria força" (Winnicott, 1971/1975, p.193).

Seguindo essa reflexão, considera-se, nesta asserção, que os confrontos entre pais e filhos adolescentes podem ser de duas naturezas: a da confusão de línguas, fonte de sofrimento psíquico intenso ao adolescente ou do conflito geracional, que é estruturante. Entende-se, então, que uma situação abole a outra, isto é, a confusão de línguas parece se fazer presente quando os pais não conseguem sustentar o conflito geracional, igualando as posições e sendo descuidados com a assimetria que deveria existir entre o mundo adulto e o mundo adolescente. Assim, observou-se que, muitas das situações causadoras de sofrimento aos jovens são aquelas nas quais os pais parecem esquecer-se do papel que deveriam desempenhar; a confusão de línguas surge como um obstáculo ao conflito geracional.

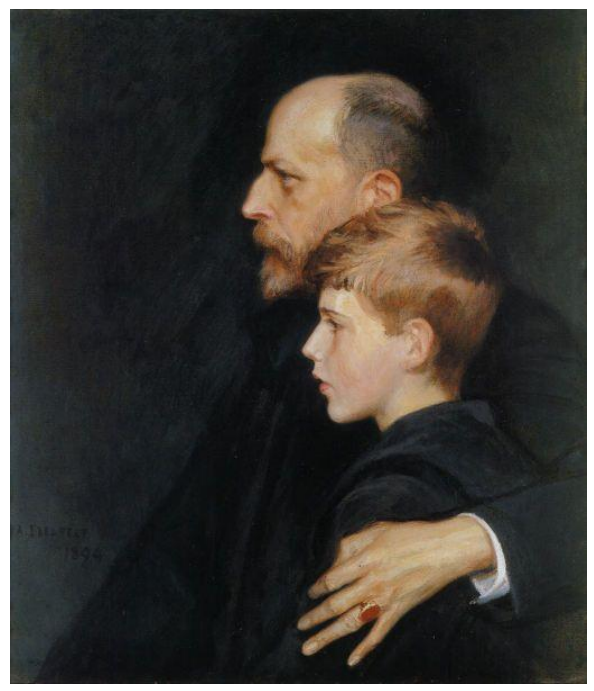

Albert Edelfelt: Portrait of Pietro ja Mario Krohnin (1894)

\section{A potencialidade traumática da confusão de línguas}

Com base no já foi que exposto, considerou-se a confusão de línguas como uma experiência essencialmente traumática, tornando necessária a reflexão sobre um conceito central na obra ferencziana e no entendimento da confusão de línguas: o trauma patogênico (Ferenczi, 1934/2011). O primeiro tempo do trauma patogênico foi chamado de choque por Ferenczi (1934/2011), e refere-se a um acontecimento que age de forma esmagadora sobre o sujeito, de maneira que ele não pode oferecer resistência. Kupermann (2019) propõe chamar este momento de tempo do indizível, marcado por um "ato deflagrador de dor e um excesso de excitação irrepresentável” (p.57), que impossibilita a criança de dar sentido a experiência sozinha. 
Após o momento do choque, ocorre a busca de ajuda por parte do sujeito em vulnerabilidade - relacionada a tendência da criança ou do adolescente de simbolizar o excesso traumático. $\mathrm{O}$ sujeito, tentando dar sentido às experiências, procura uma segunda pessoa de confiança - diferente do abusador -, que possa auxiliá-lo a dar conta da excitação pulsional irrepresentável (Ferenczi, 1934/2011). É pertinente destacar que nem sempre o sujeito violado vai contar explicitamente o que aconteceu. Ele demonstrará que precisa de ajuda da forma que conseguir, seja falando ou por meio de algum sintoma, como agressividade, diminuição do rendimento escolar ou maus-tratos aos animais, por exemplo.

Em sua releitura, Kupermann (2019) sugere chamar esse segundo tempo do trauma de tempo do testemunho, que diz respeito à tentativa do sujeito violado de buscar um testemunho adequado para o que aconteceu, "endereçando sua dor a um outro" (p.58). Então, mesmo diante da desorientação psíquica gerada pelo tempo do indizível, a criança ainda poderia ser ajudada, sendo a atitude do adulto em relação à criança que sofreu um choque determinante para o desenvolvimento, ou não, do trauma patogênico (Kupermann, 2019; Ferenczi, 1934/2011).

Nem sempre ocorre, entretanto, este acolhimento, pelo contrário, recorrentemente os adultos reagem ao pedido de ajuda com indiferença, silêncio ou castigam o sujeito vulnerável. E é justamente esse desmentido - o dizer, ou fingir, que nada aconteceu - que constitui o trauma patogênico para Ferenczi (1933/2011). Nessa direção, Kupermann (2019) entende o tempo do desmentido como o fracasso do tempo do testemunho, "quando se configura o abandono daquele que fora requisitado para autenticar e significar a violação por meio do reconhecimento da dor que se apoderou do ser da criança" (p.59).

Em outras palavras, após esse pedido de ajuda por parte do sujeito em vulnerabilidade, o tempo do desmentido se caracteriza pela quebra da confiança, pela ausência do testemunho, prevalecendo a recusa - o adulto, diante do pedido de socorro da criança, não a compreende, não acredita no testemunho, a pune ou reage com silêncio (Ferenczi, 1933/2011). Trata-se de um evento efetivamente crucial na teorização ferencziana, uma vez que é justamente o fracasso do tempo do testemunho que torna a violência sofrida efetivamente traumática.

Desta forma, entende-se que no tempo do desmentido há uma significativa perda da confiança do sujeito no mundo, na medida em que se pede ajuda justamente para alguém de importante investimento afetivo, e a resposta desse outro é marcada pelo desmentido - seja pelo silêncio, indiferença ou negação diante do pedido. Nesta direção, Pinheiro (1995) enfatiza que a criança deposita "uma confiança cega no adulto" e essa confiança fica comprometida na medida em que o adulto não corresponde às suas expectativas - que seriam de alguém que iria escutá-la, acreditaria nela e ajudaria a representar o que aconteceu. Diante desse desmentido a criança fica confusa: Será o adulto ou será ela que não merece confiança? A partir da teorização ferencziana, portanto, o trauma não é caracterizado apenas pelo excesso pulsional do choque, o pior é realmente o desmentido, ou seja, o dizer ou o fingir que nada aconteceu (Kupermann, 2019). Essa dinâmica pode repetir-se na adolescência, como observa-se no trecho abaixo, quando Breno busca ajuda na mãe para testemunhar algo da ordem do indizível:

"Eu tentei me matar entre aspas. Todo mundo fala que eu tentei me matar, mas o que eu queria era entrar em coma. Eu tava [sic] apaixonado por uma garota, meio que a gente tava [sic] ficando, só que eu não interpretando as coisas do jeito certo. Eu não tava [sic] entendendo na minha cabeça que ela queria só ficar comigo, eu tava [sic] achando que ela queria namorar comigo, e ficou nesse vai e vem por dois meses. E daí, quando ela disse que não queria mais, eu fiquei louco da cabeça! Depois disso, primeiro 
eu tentei procurar ajuda, mas como eu não tenho amigos próximos, falei pra minha mãe um pouco do que tinha acontecido. E minha mãe disse que era bobagem, que todo mundo passa por isso. Só que isso não me ajudou. Falei com um primo meu que teve os problemas dele né e ele me falou que ia na minha casa no final de semana. Mas eu não consegui esperar. E aí eu tomei uma overdose de medicamentos, tomei ácido valproico e tomei junto whisky, porque enfim, eu não me lembro de onde eu tinha ouvido falar que tomar bebidas com remédio pode dar coma. E sim, na teoria deu certo, porque eu dormi por 20 horas, então foi um mini coma" (Breno, 19 anos).

A fala de Breno parece ilustrar a tentativa de buscar um testemunho, seguida pelo tempo do desmentido (Kupermann, 2019), posto que o jovem, diante de uma dor psíquica intensa, buscou ajuda na mãe, uma figura privilegiada de investimento amoroso, porém esta agiu com indiferença. Quer dizer, a mãe se limitou a dizer que todos passam por isso, parecendo esquecer-se da idade do filho e do fato de ele estar vivendo suas primeiras experiências e frustrações amorosas. De um modo geral, é notável que os adultos, por diferentes razões que não cabem serem descritas aqui, adotam saídas que desconsideram a responsabilidade com os filhos adolescentes, prevalecendo, em suas atitudes, o desmentido ferencziano.

\section{A Carência de Relações Significativas entre Pares na Adolescência}

A escuta dos participantes denunciou uma falta de relações íntimas entre pares na adolescência, ou seja, diferentemente do que é esperado neste período, as amizades parecem não ocupar um lugar de destaque na vida destes jovens. Para a Psicanálise, as amizades ocupam um lugar privilegiado na adolescência, já que representam as primeiras escolhas exogâmicas na vida do jovem, ou seja, fora do núcleo familiar, além de possibilitarem novas identificações. Dessa forma, espera-se que as relações de amizade possuam um lugar de destaque na vida dos adolescentes, uma vez que os pares são, na maioria das vezes, os protagonistas da vida social dos jovens (Savietto \& Cardoso, 2011).

Os discursos dos entrevistados desta pesquisa mostraram, no entanto, um cenário distinto: adolescências marcadas pela superficialidade das amizades e pela dificuldade de estabelecer relações significativas. Indagou-se, assim, o que essa escassez revela sobre a vida destes jovens. A narrativa do participante Breno exemplifica este contexto:

"Nunca fui uma pessoa de sair pra balada, essas coisas assim. Mas por agora que eu tô [sic] começando aí, porque eu achei um lugar né, uma danceteria que tem, que lá tem umas músicas mais nerds que é o tipo de música que eu gosto. Mas voltando ao assunto, eu nunca fui uma pessoa muito de sair de casa, eu nunca tive verdadeiros amigos assim. Porque eu nunca fui muito de socializar, eu sempre fui um cara mais quietão, mais parado, tipo aquele cara que chega numa festa e procura um lugar pra sentar" (Breno, 19 anos).

A declaração de Breno expõe a dificuldade do adolescente de estabelecer laços de modo geral e de relacionar-se com os pares. A seguir, o discurso de Sara reafirma a superficialidade das relações horizontais:

"Eu sempre fui uma pessoa que me sentia meio fora dos grupos, eu sentia que tinham vários grupos e eu transitava entre todos, mas eu nunca tinha um. E até hoje eu sou assim. Me sinto meio perdida. Eu não consigo assim passar um mês inteiro com o pessoal da minha escola. Se eu tô [sic] todo dia com o pessoal da minha escola, eu não 
vou sair com eles no final de semana. Eu vou sair um dia com cada grupo de pessoas. Eu sinto uma facilidade muito grande de ter amizades, mas, ao mesmo tempo, as conexões não são profundas e fortes. Parece que eu não posso me deixar depender muito de uma pessoa na minha vida" (Sara, 16 anos).

A partir desses relatos, constatou-se que nem sempre se trata de uma ausência total de amizades na vida do adolescente, mas da inexistência de amigos íntimos e merecedores de confiança. Na próxima vinheta, o participante Arthur também confessa a falta que as amizades fazem em sua vida, e associa essa ausência à sua maturidade precoce:

"Por tudo que eu passei, eu acabo tendo uma cabeça de velho mesmo. E é complicado, e às vezes eu queria sair, conhecer gente, fazer amigos, desabafar, tomar uma cerveja. E eu nem tô [sic] falando da fase de festa, porque eu passei tanto dessa fase que eu já nem gosto mais. Eu gostaria mais de ir na casa [sic] de alguém, tocar violão, tomar uma cerveja, escutar música, mas eu não tenho isso" (Arthur, 19 anos)

Para refletir sobre esse contexto, recorda-se que Ferenczi (1934/2011) dividiu o trauma em dois tempos: sendo o primeiro definido por um choque e o segundo caracterizado pela busca de ajuda por parte do sujeito em vulnerabilidade. A tendência da criança ou do adolescente é a de simbolização e, para tanto, recorrerá a uma pessoa de confiança, que possa auxiliar o sujeito a dar conta da excitação pulsional irrepresentável (Ferenczi, 1934/2011).

Atenta-se aqui para uma possível diferença entre a confusão de línguas que envolve as crianças e a que envolve os adolescentes. A criança, necessariamente, teria que buscar ajuda em um adulto, uma vez que seu ambiente ainda está restrito a poucas pessoas de confiança - normalmente o núcleo familiar. Já no caso dos adolescentes, a amizade poderia suprir o que as relações verticais não oferecem, por exemplo.

Desse modo, um jovem poderia buscar em um amigo, ou em alguém da mesma idade, a possibilidade de compartilhar o seu sofrimento, e isso poderia suprir o valioso papel do tempo testemunho enfatizado por Kupermann (2019). De acordo com os entrevistados desta pesquisa, os jovens não buscam, ou não encontram nas relações horizontais a possibilidade de testemunharem o seu sofrimento, o que talvez poderia evitar que a experiência de angústia se instaurasse como traumatizante.

Evoca-se, ainda, o terceiro tempo da traumatogênese, o tempo do desmentido quando há uma quebra da confiança no encontro com o outro. Esse cenário pode ser notado no trecho abaixo, em que Arthur conta estar muito frágil e tenta buscar ajuda em sua mãe, mas não é amparado:

"Porque na escola, eu sofri muito. E a minha mãe era aquele tipo de pessoa que dizia assim "ah, se tão fazendo isso com você, é porque você dá motivo, porque você faz também". E aí foi muito ruim, e não foi sabe, se fosse um ou dois ali, tudo bem, uma roda e tal, mas era toda a sala. Então eu via como se fosse toda a sala contra mim. E eu não gostava de ir pra escola, porque o pessoal, eles ficavam... me zoavam muito, me batiam... então era complicado. Aí eu já cheguei a falar com a diretora, falava com a diretora várias vezes, só que a diretora também não dava atenção. Era muito complicado, na educação física eu era o alvo de tudo. Por exemplo, no jogo dos três cortes, no vôlei, a gente ia jogar, e sempre cortavam em mim. Todos em mim, todos. E na sala de aula, eles passavam assim, saiam lá do fundo da classe deles e passavam por mim e me davam um tapa na cabeça. E me xingavam o tempo todo. E eu não fazia 
nada, porque se eu fizesse eles iam me espancar, eu via como se fosse toda a sala contra mim" (Arthur, 19 anos).

Com base nesse e em outros enunciados do participante, observa-se que, além de Arthur não ter nenhum amigo, era extremamente hostilizado pelos colegas de classe. Diante do sofrimento experimentado, o jovem resolve contar o que estava vivenciando para a diretora do colégio e para a sua mãe, esperando que fosse amparado de alguma forma; no entanto, vê-se ignorado pelos adultos e, ainda, culpabilizado pela mãe, o que aumenta a sua angústia. Entende-se que, na história de Arthur, a mãe não acolher a sua dor torna-se mais devastador do que o bullying em si, e é isto que constitui, de fato, o trauma patogênico: pedir ajuda para uma pessoa em quem se confia, mas perceber que não tem com quem contar.

Essa carência de amigos íntimos na vida desses adolescentes pode estar relacionada à falha nos processos de construção das primeiras relações íntimas, de apoio e de confiança - características que normalmente descreveriam as amizades entre adolescentes. Os sujeitos desta pesquisa, pelas dificuldades importantes que experimentam na relação com os seus pais, talvez também possuam dificuldade de confiar nos seus pares.

\section{Considerações Finais}

Apesar da luta dos adolescentes pela autonomia, nunca é demais lembrar que os jovens ainda são dependentes e necessitam do auxílio dos adultos, sobretudo dos pais, no enfrentamento dos momentos de oscilação próprios desta fase da vida. Por mais fundamental que seja conceder espaço para que os adolescentes conquistem sua independência, é imprescindível que as figuras parentais também ofereçam segurança e cuidado, principalmente nos momentos de sofrimento - que pode se manifestar direta ou indiretamente. Apesar da manifesta resistência e rebeldia, o adolescente precisa e deseja receber limites vinculados ao cuidado, visto que, se as posições são sustentadas e bem diferenciadas, elas se tornam protetivas e proporcionam contenção para o jovem, que encontra mais segurança para desenvolver confiança no ambiente e em si mesmo. Neste sentido, o exercício da autoridade por parte dos pais é constitutivo e saudável para o adolescente por diversos fatores, especialmente para que seja possível o exercício da ambivalência (Winnicott, 1971/1975), como ilustrado por Ferenczi (1928) em um interessante exemplo:

Lembro-me de um incidente com um dos meus sobrinhos pequenos, a quem tratava com toda a suavidade que, em meu entender, convém a um psicanalista. Aproveitou para começar a atormentar-me; por fim, passou a agredir-me. A psicanálise não me ensinou que deveria deixar-me agredir. Portanto, tomei-o em meus braços e, segurando-o com firmeza para impedi-lo de se mexer, disse-lhe: "Bata em mim agora se conseguir". Ele tentou, mas, não o conseguindo, pôs-se a injuriar-me, dizendo que me detestava. Respondi-lhe: "Muito bem, continue, tudo isso você pode pensar e dizer, mas não tem o direito de me bater". Finalmente, reconheceu a minha superioridade e o seu direito de me agredir unicamente em imaginação. Após o que nos separamos como bons amigos (Ferenczi, 1928/2011, p. 33).

Mas diante das circunstâncias denunciadas pelas entrevistas, em que a diferença entre adolescente e adulto parece, com frequência, se esvair, questiona-se: quem estaria ocupando o lugar de responsável por sustentar bons embates e ajudar o jovem a 
compreender o que sente e experimenta? Winnicott (1963/1983) postulou a ideia de solidão que se refere à saudável capacidade de estar só, que diz respeito a uma aquisição desejável a todas as pessoas, sobretudo para o adolescente que possui uma demanda de solidão no que diz respeito aos pais; porém, os adolescentes entrevistados se encontram em uma situação de solidão peculiar, marcada por um abandono potencialmente traumático, onde não há com quem lutar, não há resistência por parte do adulto, e, portanto, não sobra lugar para a vivência do conflito geracional.

Como consequência, além da potencialização do sofrimento próprio dessa fase, não sabem se o mundo é confiável, e compreende-se que isto pode estar relacionado à confusão de línguas que permeia as relações entre adolescentes e suas figuras parentais desta pesquisa. Quando se percebe que as figuras consideradas mais importantes na vida do adolescente, na realidade, não se mostram dignas de confiança, a segurança do sujeito fica prejudicada de um modo geral. Pressupõe-se, assim, que a carência de relações íntimas e significativas entre pares também pode estar ligada a esse dilema: se nem a pessoa mais importante da minha vida mostrou-se confiável, em quem eu poderia confiar?

Por outro lado, parece que as famílias encontram-se também desamparadas no que diz respeito à educação dos filhos, oscilando entre comportamentos permissivos em excesso ou supridores em excesso, o que denuncia uma dificuldade de sustentar a posição de adulto, propiciando limites vinculados ao cuidado (Cardoso, 2006). Sobre este cenário, reflete-se que, em 1930, no texto "O mal-estar na civilização", Freud já chamava atenção para o fato de que a ausência de uma figura de autoridade de destaque na sociedade poderia representar um perigo. Assim, como uma sociedade necessita de uma autoridade que transmita segurança e dite as leis, Savietto (2012) alerta para a importância da função de autoridade das figuras parentais e para o não apagamento das diferenças geracionais, as quais oferecem suporte e segurança aos adolescentes. A pesquisa não aprofundou nessa questão, que diz respeito à dificuldade das famílias com seus adolescentes, mas evidencia um tema merecedor de futuro aprofundamento. Aqui, resta destacar que os adultos deveriam estar servindo como modelos aos jovens, mas, nas circunstâncias atuais, os lugares dos pais e dos filhos encontram-se frequentemente mal definidos.

Para finalizar, retornamos a questão inicial: o lugar atribuído aos pais no sofrimento do adolescente. Com base nos quatro adolescentes entrevistados, é um lugar que pode ser traumático ou constitutivo - constitutivo quando, apesar dos conflitos, existe delimitação de posições, respeito, cuidado, afeto, limites; traumático quando é marcado pela inversão ou igualamento de posições, de responsabilidades, humilhações, negligência, indiferença. E esse lugar pode, como bem mostraram os resultados da pesquisa, ser decisivo no que diz respeito a outras áreas da vida do adolescente e na sua capacidade de estar e investir no mundo de forma geral. Apesar desta investigação não ter o propósito, e muito menos o poder de abarcar toda a complexidade que esta questão evoca, a trajetória que percorremos evidenciou que a relação com os pais se torna fonte de intenso e excessivo sofrimento para o adolescente quando é marcada pela confusão de línguas e pelo engodo de que um adolescente não precisa ser cuidado. A partir dessa trajetória, a pesquisa reafirmou alguns postulados já existentes, mas também apontou para novas vias de análise de um fenômeno complexo e merecedor de constante atualização e aprofundamento teórico.

\section{Referências}

Birman, J. (2006). Tatuando o desamparo: A juventude na atualidade. Em MR Cardoso (Org.), Adolescentes (pp. 25-43). São Paulo: Escuta. 
Brasil (1990). Lei 8.069, de 13 de julho de 1990. Estatuto da Criança e do Adolescente. Brasília: Ministério da Justiça.

Cardoso, M. R. (2011). Adolescentes. São Paulo: Escuta.

Erickson, F. (1997). Métodos cualitativos de investigación sobre la enseñanza. Em M Wittrock (Org.), La investigación de la enseñanza (pp. 195-301). Barcelona: Paidós.

Ferenczi, S. (2011). A adaptação da família à criança. In A. Cabral (Trad.), Psicanálise IV (pp. 111-135). São Paulo: Martins Fontes. (Original publicado em 1928)

Ferenczi, S. (2011). Confusão de língua entre os adultos e a criança. In A. Cabral (Trad.), Psicanálise IV (pp. 111-135). São Paulo: Martins Fontes. (Original publicado em 1933)

Ferenczi S. (2011). Reflexões sobre o trauma. In A. Cabral (Trad.), Psicanálise IV (pp. 126-135). São Paulo: Martins Fontes. (Original publicado em 1934)

Freud, S. (2006). Três ensaios sobre sexualidade. In J. Salomão (Ed.), Edição Standard Brasileira das Obras Psicológicas completas de Sigmund Freud, (pp. 119-209). Rio de Janeiro: Imago. (Original publicado em 1905)

Freud, S. (1918). Conferências introdutórias sobre psicanálise: Conferência X Simbolismo 117 nos sonhos. In S. J. Strachey (Ed.), Edição Standard Brasileira das Obras Psicológicas completas de Sigmund Freud (p. 287-539). Rio de Janeiro: Imago (Original publicado em 1917)

Freud, S. (2006). O mal-estar na civilização. In J. Salomão (Ed.), Edição Standard Brasileira das Obras Psicológicas completas de Sigmund Freud, vol. 21 (pp. 67-150). Rio de Janeiro: Imago. (Original publicado em 1930 [1929])

Kupermann, D. (2006). A progressão traumática: algumas consequências para a clínica na contemporaneidade. São Paulo: Revista Percurso, 18(36), 25-32.

Kupermann, D. (2007). Sobre o final da análise com criança e adolescentes. São Paulo: Estilos da Clínica.

Kupermann, D. (2019). Por que Ferenczi hoje? São Paulo: Zagadoni.

Mannoni, O. (1996). A adolescência é analisável? Em AI Corrêa (Org.), Mais tarde... é agora! Ensaios sobre a adolescência (pp. 20-41). Salvador: Ágalma.

Nasio, J. -D. (2010). Como agir com um adolescente difícil?: Um livro para pais e profissionais. Rio de Janeiro: Jorge Zahar.

Nunes, M. L. T. (2004). Pesquisa qualitativa: abordagem, coleta e análise de dados. Em D Azevedo, MC Barros \&, M Muller (Org.), Psicologia e interdisciplinaridade: uma experiência na educação à distância (pp. 303-314). Porto Alegre: EDIPUCRS.

Oliveira, D. M. D., \& Fulgêncio, L. P. (2010). Contribuições para o estudo da adolescência sob a ótica de Winnicott para a Educação. Belo Horizonte: Psicologia em Revista, 16(1), 64-80.

Pinheiro, T. (1995). Ferenczi: do grito à palavra. Rio de Janeiro: Jorge Zahar.

Savietto, B. B. \& Cardoso, M. R. (2006). Adolescência: ato e atualidade. Fortaleza: Revista Mal-estar e Subjetividadde, 6(1), 15-43.

Savietto, B. B. (2012). Juventude e família na contemporaneidade: um desamparo sem fim? Uberlândia: Gerais: Revista Interinstitucional de Psicologia, 5(1), 23-35.

Turato, E. R. (2011). Tratado da metodologia de pesquisa clínico-qualitativa: construção teórico-epistemológica, discussão comparada e ampliação das áreas da saúde e humanas. Rio de Janeiro: Vozes.

WHO, World Health Organization. (1986). Young People's Health - a Challenge for Society. Report of a WHO Study Group on Young People and Health for All. Technical Report Series 731. Geneva: WHO. 
Winnicott, D. W. (1975). Conceitos contemporâneos de desenvolvimento adolescente e suas implicações para a educação superior. Em DW Winnicott, O brincar e a realidade (pp. 219-238). Rio de Janeiro: Imago. (Original publicado em 1971)

Winnicott, D. W. (1983) O atendimento hospitalar como complemento de psicoterapia intensiva na adolescência. Em DW Winnicott, O ambiente e os processos de maturação (pp. 218-224). São Paulo: Martins Fontes (Original publicado em 1963)

Winnicott, D. W. (1990). Natureza humana. Rio de Janeiro: Imago. (Original publicado em 1988)

Winnicott, D. W. (2000). Preocupação materna primária. Em DW Winnicott, Da pediatria à psicanálise: obras escolhidas (pp. 399-406). Rio de Janeiro: Imago. (Original publicado em 1956)

Winnicott, D. W. (2013). Adolescência. Transpondo a zona das calmarias. Em DW Winnicott, A família e o desenvolvimento individual. São Paulo: Martins Fontes. (Original publicado em 1961)

Winnicott, D. W. (2016). A juventude não dormirá. Em DW Winnicott, Privação e delinquência (pp. 177-183). São Paulo: Martins Fontes. (Original publicado em 1964)

Winnicott, D. W. (2016). A imaturidade do adolescente. Em DW Winnicott, Tudo começa em casa (pp. 145-165). São Paulo: Martins Fontes. (Original publicado em 1968)

\section{Notas:}

1. Consideraram-se pais quaisquer sujeitos que exerçam a função de figura parental na vida do adolescente.

2. Nomes fictícios.

Citação/Citation: Hentz, R.; Kupermann, D. (2021). O lugar atribuído aos pais no sofrimento do adolescente. Trivium: Estudos Interdisciplinares (Ano XIII, Ed.2), pp. 320. 